\title{
SITE RESPONSE IN GUWAHATI REGION USING STANDARD SPECTRAL RATIO
}

\author{
Sasanka Borah ${ }^{1}$, Diganta Goswami ${ }^{2}$, Jayanta Pathak ${ }^{3}$ \\ ${ }^{1}$ Research Scholar, Department of Civil Engineering, Assam Engineering College, Assam, India \\ ${ }^{2}$ Associate Professor, Department of Civil Engineering, Assam Engineering College, Assam, India \\ ${ }^{3}$ Professor, Department of Civil Engineering, Assam Engineering College, Assam, India
}

\begin{abstract}
This study attempts, through a very limited number of data to explain the requirement of a detailed seismic analysis of the western part of the Guwahati metropolitan region of Assam, India, which falls under seismic zone-V(IS:1893-2002) and consists of mainly alluvial deposits. This study carries out a Site Response study of Western part of Guwahati by employing Standard Spectral Ratio (SSR) method, which is a reference site method, where the ratio of Fourier spectrum of ground motions recorded at a soil site to that of ground motions recorded at a nearby reference site (rock site) is obtained to define the site response. Significant site response in terms of site amplification is observed in the frequency range of 0.1 to $1.00 \mathrm{~Hz}$, which concretes the necessity of a detailed analysis program for the region.
\end{abstract}

Keywords: Site Response, Standard Spectral Ratio (SSR)

\section{INTRODUCTION}

One of the most easy, popular, widely accepted and used reference site method to evaluate site response is the Standard Spectral Ratio (SSR) method (Mittal et. al., 2013). It has been used by many authors to determine the site response (Field, E. and Jacob, K.H., 1995, Reipl, et. al., 1988, Lermo \& Chavez Garcia, 1994a, Chavez-Garcia \& Cuenca, 1998, Raptakis et. al., 1998a). The SSR is a technique where the site response is defined as the ratio of the Fourier amplitude spectrum of ground motions recorded at a soil-site to that of ground motions recorded at a rocksite record located nearby, from the same earthquake and component of motion (Borcherdt, 1970, Pitilakis, 2012).

\subsection{BASIC ASSUMPTIONS OF SSR}

In this method it is assumed that earthquake records obtained from the reference site (an earthquake recording station located on a hard rock outcrop) are free from site effects and contains the same source properties and when the two sites are closely located, the path or propagation effects are also same for the pair of records. Hence, the ratio of the Fourier amplitude spectra of sedimentary site to reference site expresses the local site effects or in other terms amplification at the sedimentary site. Alternatively, it can be said that the technique depends on two basic assumptions (Lang, 2004):

1. The source and paths effects at both sites are similar,

2. The reference site has a negligible site response, that is, its spectrum is flat.

The first assumption requires that the distance between both sites is limited in order to have a similar wave field (with similar incidence angles and azimuths) arriving at the two sites. This effect can also be reached with increasing sourcereceiver distance compared to the distance between the two recording sites (Field et. al., 1992).

The second assumption implies that the earthquake record on the rock site, which usually is a free field station on the ground surface, is almost equivalent to the input motion at some depth, not taking into account the free-surface effects (Lermo and Chavez-Garcia, 1994).

\subsection{THE SSR METHOD}

The Standard Spectral Ratio (SSR) method is defined as the ratio of ground motions records of that of a soil-site to that of a rock site, where the rock site is used as a reference site (Figure 1). It is assumed that earthquakes recorded on the reference site (i.e. recorded on a station placed on outcropping hard bedrock) contains the same source and propagation effects as that of the records from the other sites that is:

Where,

$$
\begin{gathered}
\text { Standard Spectral Ratio }(S S R)=\frac{U_{i j}(x, y)}{U_{i k}(x, y)} \\
=\frac{S_{i}(x) Z(x)_{j} A_{i j}(x, y)}{S_{i}(x) Z(x)_{k} A_{i k}(x, y)}
\end{gathered}
$$

$\mathrm{U}_{\mathrm{ij}}(\mathrm{x}, \mathrm{y})=$ Fourier Amplitude of the ground motion observed at a soil site $\mathrm{j}$ for an event $\mathrm{i}$,

$\mathrm{S}_{\mathrm{i}}(\mathrm{x}) \quad=$ source function.

$\mathrm{Z}_{\mathrm{i}}(\mathrm{x}) \quad=$ response of the site.

$\mathrm{A}_{\mathrm{ij}}(\mathrm{x}, \mathrm{y})=$ Attenuations function.

$x=$ the frequency,

$y=$ distance from epicenter and

$k=$ reference station. 
It is to be noted that as schematically shown in Figure 1, the earthquake ground motion recorded at one station is considered as the resultant of three parameters, the source $S_{i}(x)$, the path $A_{i j}(x, y)$ and local site response $Z_{j}(\mathrm{x})$. If the recording stations are located nearby and it is assumed that the reference station is not at all influences by local site conditions or site effects, then and $A_{i j}(x, y) \approx A_{i k}(x, y)$. Hence it can be said that the ratio of spectral do directly provide the site response at the soil site. However, the major limitation of this method is that rock site may also have its own site specific response. Furthermore, a rock site which may be considered as a good reference site might be located too far away from the target site therefore not permitting assumption of similarity in the wave propagation paths of the two recording stations, or, the reference station may not be located at all.

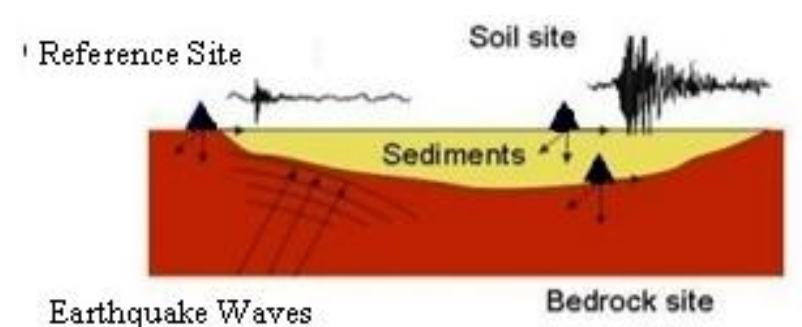

Fig-1: Schematic description of the SSR Method (after Parolai, 2012 and modified)

\section{AREA OF STUDY}

Guwahati is the largest city in the north east region of India. The whole of northeast India falls in zone V of the seismic hazard zonation map (IS:1893-2002) of India, the highest vulnerable zone in the country. This can be substantiated by the fact that devastating earthquake of Mw 8.1 in 1897 and Mw 8.6 in 1950 has occurred in this region which resulted in the change of topography of the area.

The Guwahati city being located almost at the center of the region, acts as the gateway and transit point for communication and transportation for the people coming into and going out of the northeastern region of India. Being a very important transit point in the region, Guwahati also has witnessed rapid changes in terms of urban infrastructure development and other allied developments.

However a very few studies has been carried out in this region to determine the response the local soil deposits to seismic waves. It is worth mentioning that a study Microzonation of Guwahati city, 2008 was carried out which concentrated on developing seismic maps of the region apart from determining the liquefaction potential of the Guwahati city.

\section{PRESENT STUDY}

The present study concentrates on the western part of Guwahati region encompassing and extending further westward to Boko-Palashbari and Goalpara which are at a distance of approximately $50 \mathrm{~km}$ and $100 \mathrm{~km}$ respectively from Guwahati city. A comparison of site response of Guwahati Central to western Guwahati area of BokoPalashbari and far western area of Goalpara region is presented in this study.

\section{DATA FOR STUDY}

The seismological (acceleration time history) data required for the study is obtained from PESMOS, Department of Earthquake Engineering, IIT Roorkee. The data is available for download from the website of PESMOS, Program for Excellence in Strong Motion Studies (www.pesmos.in). The data can be downloaded by registering in the website.

All downloaded accelerogram were processed by computer programs developed for the purpose (Kumar et. al, 2012). The processing involved baseline correction of the record and rotation of the horizontal components to get N-S and E$\mathrm{W}$ components. As the natural frequency of the sensors is on the higher side $(200 \mathrm{~Hz})$ instrument correction of records was not performed (Kumar et. al, 2012). The records were also low pass filtered at a cutoff frequency of $35 \mathrm{~Hz}$.

\subsection{SELECTION OF REFERENCE \& SOIL SITE}

Earthquakes recorded at Nongstoin and soil sites as mentioned in Table $1 \&$ Table 2, obtained from PESMOS were used as input motion for the analysis. Nongstoin is located at a distance of approximately $100 \mathrm{~km}$ from the study area and is classified as site class A (Mittal et. al., 2012) having shear wave velocities within the range of $700 \mathrm{~m} / \mathrm{sec}$ to $1400 \mathrm{~m} / \mathrm{sec}$.

Table 1: Reference site motions

\begin{tabular}{|c|c|c|c|}
\hline Earthquake & $\begin{array}{c}\text { Magnitude } \\
(\mathrm{Mw})\end{array}$ & $\begin{array}{c}\text { Focal Depth } \\
(\mathrm{km})\end{array}$ & $\begin{array}{c}\text { Epicentral } \\
\text { Distance }(\mathrm{km})\end{array}$ \\
\hline 11 Aug.09 & 5.6 & 22 & 378 \\
\hline 03 Sep.09 & 5.9 & 100 & 363 \\
\hline 21 Sep.09 & 6.2 & 8 & 197 \\
\hline 29 Oct.09 & 5.2 & 5 & 197 \\
\hline 29 Oct.09 & 4.2 & 10 & 174 \\
\hline
\end{tabular}

Table 2: Epicentral distances (in km) of Soil \& Reference sites

\begin{tabular}{|c|c|c|c|c|}
\hline \multirow{2}{*}{ Earthquake } & $\begin{array}{c}\text { Boko-P } \\
\text { (Soil } \\
\text { site) }\end{array}$ & $\begin{array}{c}\text { Guwahati- } \\
\text { Central } \\
\text { (Soil site) }\end{array}$ & $\begin{array}{c}\text { Goalpara } \\
\text { (Soil } \\
\text { site) }\end{array}$ & $\begin{array}{c}\text { Nongstoin } \\
\text { (Ref. site) }\end{array}$ \\
\cline { 2 - 5 } & $\begin{array}{c}25.97 \mathrm{~N} \\
91.23 \mathrm{E}\end{array}$ & $\begin{array}{c}26.19 \mathrm{~N} \\
91.74 \mathrm{E}\end{array}$ & $\begin{array}{c}26.15 \mathrm{~N} \\
90.62 \mathrm{E}\end{array}$ & $\begin{array}{c}25.52 \mathrm{~N} \\
91.26 \mathrm{E}\end{array}$ \\
\hline 11 Aug.09 & 400 & 366 & 463 & 378 \\
\hline 03 Sep.09 & 388 & 356 & 450 & 363 \\
\hline 21 Sep.09 & 148 & 125 & 153 & 197 \\
\hline 29 Oct.09 & + & + & 147 & 197 \\
\hline 29 Oct.09 & + & + & 80 & 174 \\
\hline
\end{tabular}




\section{METHODOLOGY}

From the earthquake events a total of 16 earthquake recordings (as in Table 2) having three components of motion, i.e. E-W (East-West), N-S (North-South) and VT (Vertical) were selected for the analyses. Of these 11 were related soil sites (Boko-Palashbari, Goalpara and GuwahatiCentral) and 5 were related to reference site (Nongstoin).

Complete duration of all the records were Fourier transformed to obtain the Fourier Amplitude Spectra (FAS) of the respective components by using the software code DEEPSOIL (Hashash et. al., 2015). The

The ratio of smooth Fourier spectrum of soil site to reference site is then obtained and plotted on the semi-log plot with frequency as the abscissa and spectral ratio as the ordinates. The amplitude of the ratio gives the extent of site amplification by the given SSR method.

\section{RESULTS}

Figure 2, $3 \& 4$ gives the SSR plot of EW- component of Guwahati-Central, Boko-Palashbari and Goalpara respectively. Similar plot of NS and VT component of earthquake motions were also obtained and are shown in Figure 5,6,7,8,9\&10 respectively. Table 3 lists the results of various components of earthquakes for the three sites i.e., Guwahati-Central, Boko-Palashbari and Goalpara respectively.

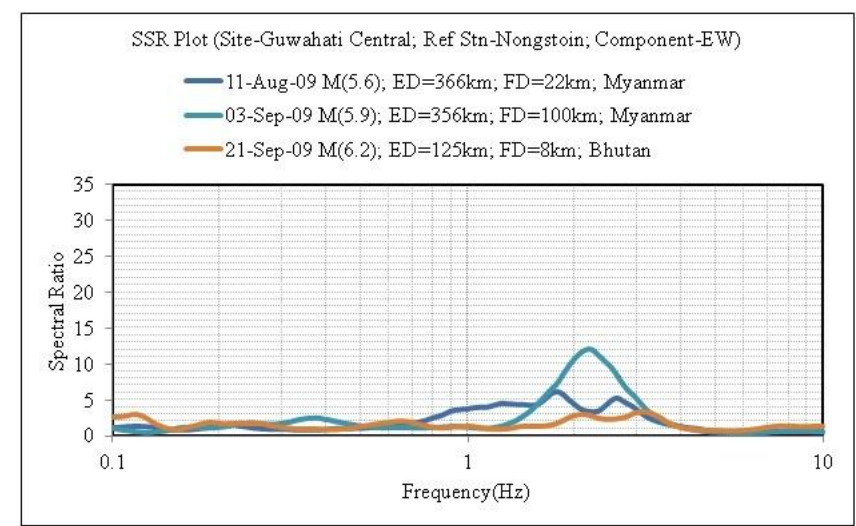

Fig-2: SSR Plot, Guwahati-Central, EW Component

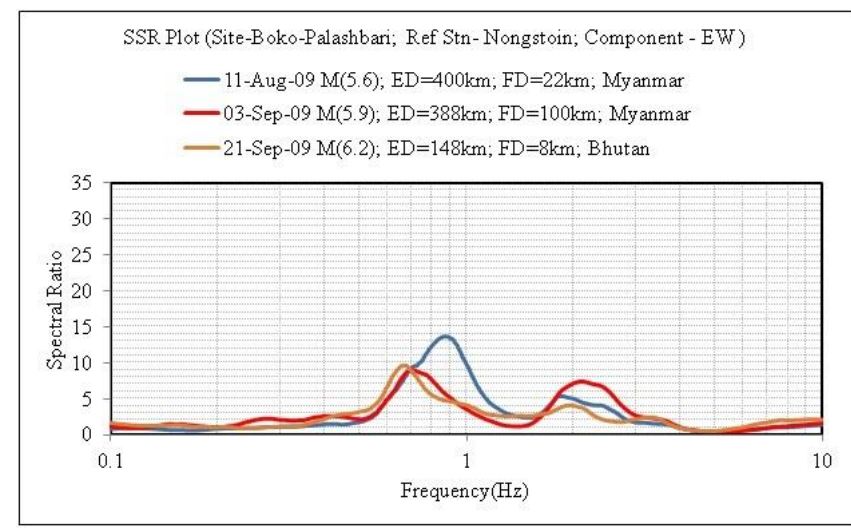

Fig-3: SSR Plot, Boko-Palashbari, EW Component

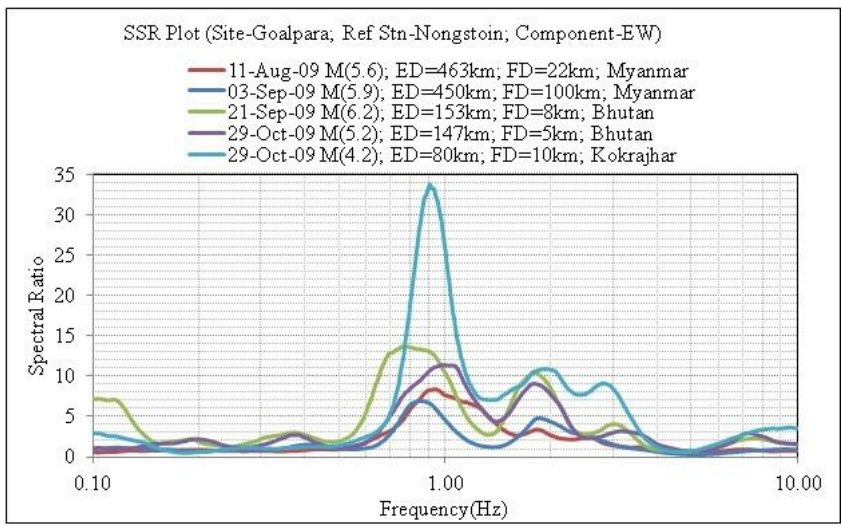

Fig-4: SSR Plot, Goalpara, EW Component

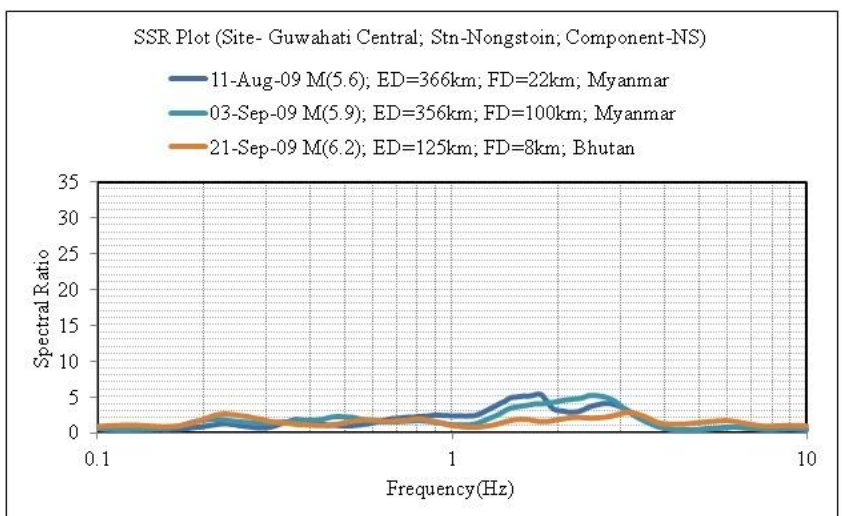

Fig-5: SSR Plot, Guwahati-Central, NS Component

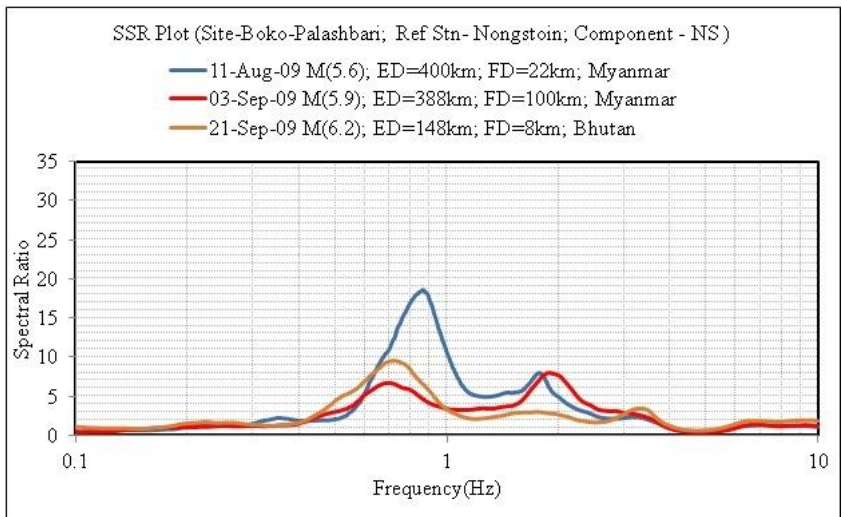

Fig-6: SSR Plot, Boko-Palashbari, NS Component

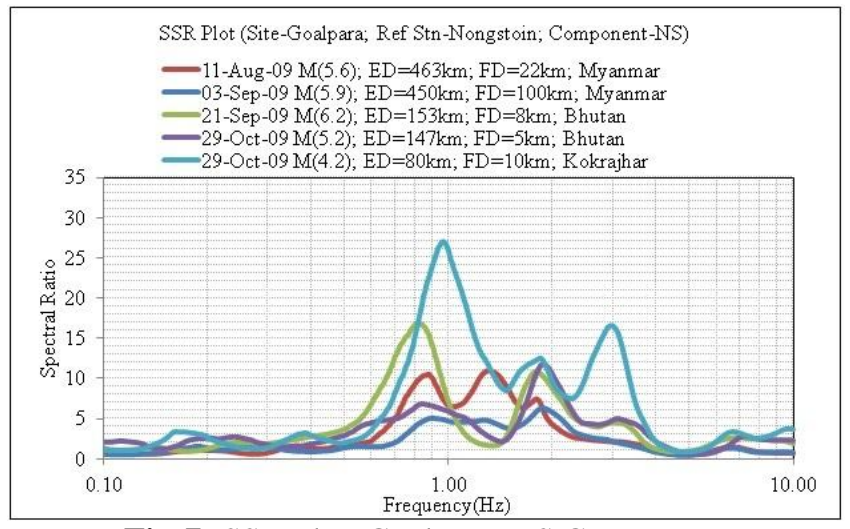

Fig-7: SSR Plot, Goalpara, NS Component 


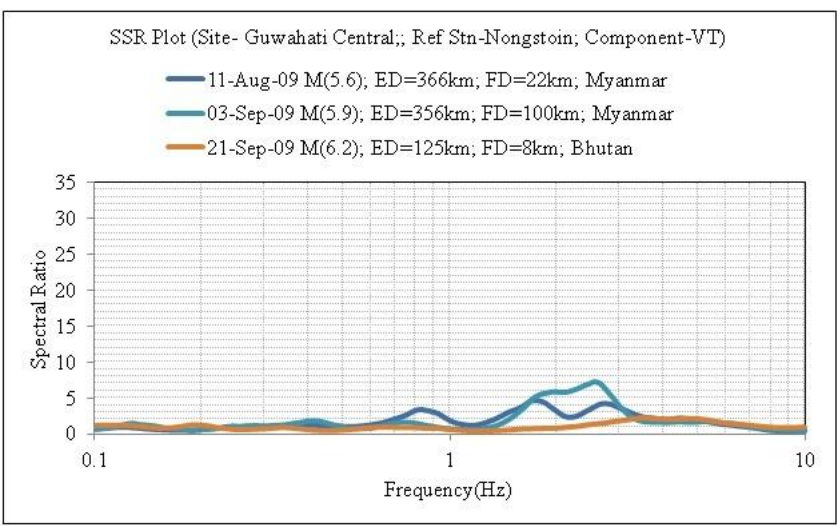

Fig-8: SSR Plot, Guwahati-Central, VT Component

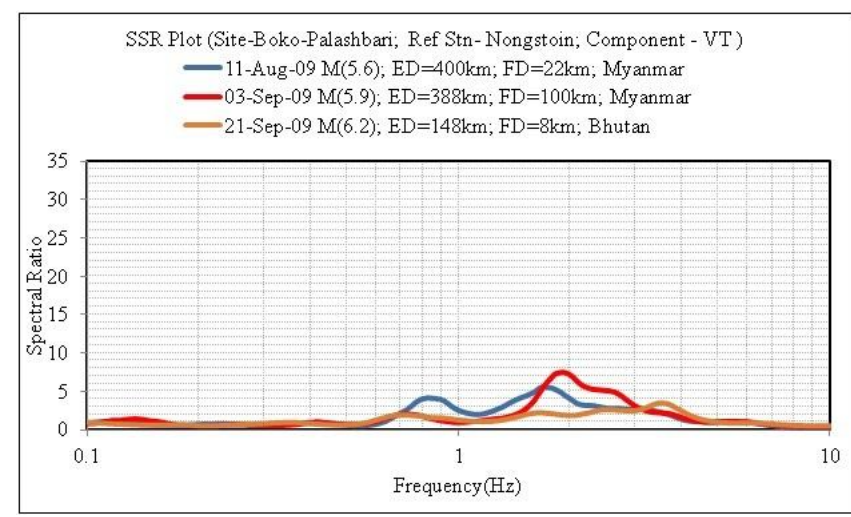

Fig-9: SSR Plot, Boko-Palashbari, VT Component

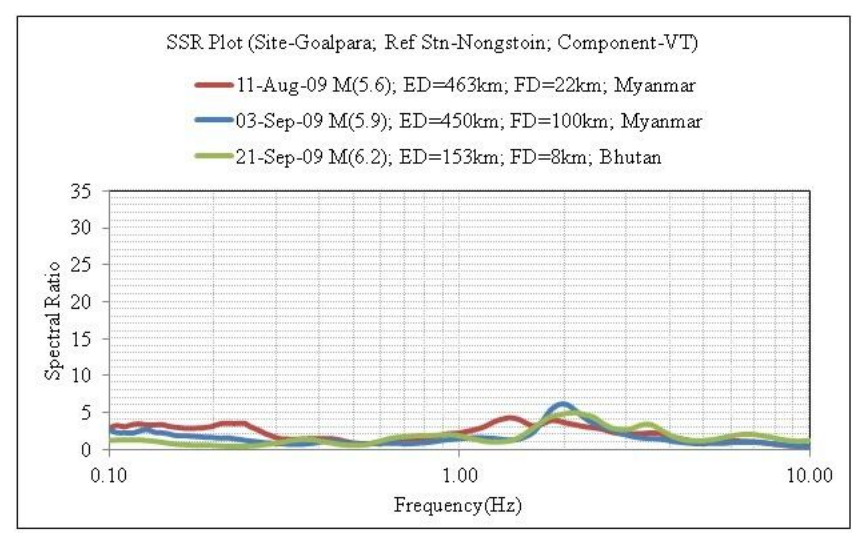

Fig-10: SSR Plot, Goalpara, VT Component

Table 3: Peak Site amplification in frequency range

\begin{tabular}{|c|c|c|c|}
\hline \multirow{2}{*}{ Site } & \multicolumn{3}{|c|}{ Peak Site Amplification in frequency range } \\
\cline { 2 - 4 } & $0.1-1.0 \mathrm{~Hz}$ & $1.0-3.0 \mathrm{~Hz}$ & $3.0-10.0 \mathrm{~Hz}$ \\
\hline $\begin{array}{c}\text { Guwahati- } \\
\text { Central }\end{array}$ & 3.67 & 12.16 & 5.14 \\
\hline $\begin{array}{c}\text { Boko- } \\
\text { Palashbari }\end{array}$ & 18.59 & 11.33 & 3.56 \\
\hline Goalpara & 33.74 & 25.79 & 16.60 \\
\hline
\end{tabular}

Peak site amplification are given in Table 3 for the following group of frequency range, G1 $(0.1-1.0 \mathrm{~Hz}), \mathrm{G} 2$ $(1.0-3.0 \mathrm{~Hz})$ and $\mathrm{G} 3(3.0-10.0 \mathrm{~Hz})$ for EW, NS \& VT components respectively. These frequency ranges are considered based on the fact that the natural frequencies of buildings having more than 10 storey falls in the G1 group, 3-10 storey buildings falls in the G2 group while 1-3 storey buildings generally fall in the G3 group. Frequency less than $0.1 \mathrm{~Hz}$ and greater than $10.0 \mathrm{~Hz}$ is not considered in this study because of their lesser amount significance in this study as well as in practical engineering.

\section{CONCLUSIONS}

It can be seen from Table 3 that site amplification for Guwahati-Central site is highest at frequency range $1-3 \mathrm{~Hz}$ while for Boko-Palashbari and Goalpara region the frequency range $0.1-1.0 \mathrm{~Hz}$ shows highest site amplification. The shift of corresponding peak amplification to lower frequency range indicates that the consistency of the soil layer in Boko-Palashbari and Goalpara is soft as compared to that of the Guwahati-Central. This will govern the structural response and performance of buildings of certain height and configuration having natural frequency close to the range predominant frequency of the site under consideration. .

Although the study indicates a high value of amplification obtained from a very limited number of data, it must be kept in mind that this study intends only to explain the significance and importance of a detailed analysis program to understand the seismicity of the western part of Guwahati region in terms of local site amplification and related damage probability to proposed built environment. This study gives a indication that detailed analysis is the need of the hour considering the importance of the region.

\section{REFERENCES}

[1]. Borcherdt, R.D. (1970), "Effects of local geology on ground motion near San Francisco Bay", Bulletin of the Seismological Society of America, 1970, 60, pp. 29-61.

[2]. Chavez-Garcia, F.J. \& Cuenca, J. (1998), "Site Effects and Microzonation in Acapulco", Earthquake Spectra, (14)1, pp. 75-94.

[3]. Lang, D.H. (2004), "Damage potential of seismic ground motion considering local site effects", Ph.D Thesis, Bauhaus-University Weimar

[4]. Field, E. H., K. H. Jacob, and S. E. Hough (1992), "Earthquake site response estimation: a weak-motion case study", Bulletin of the Seismological Society of America, 82, pp. 2283-2307

[5]. Field, E.H. \& Jacob, K.H. (1995), “A Comparison and Test of Various Site Response Estimation Techniques, including three that are not Reference-Site Dependent", Bulletin of the Seismological Society of America, (85)4: pp.1127-1143.

[6]. Hashash, Y.M.A., Musgrove, M.I., Harmon, J.A., Groholski, D.R., Phillips, C.A., and Park, D. (2015), "DEEPSOIL 6.1, User Manual".

[7]. IS:1893(Part-I)-2002, "Criteria for Earthquake Resistant Design of Structures”, Fifth Revision. 
[8]. Kumar, A., H. Mittal, R. Sachdeva, and A. Kumar (2012), "Indian strong motion instrumentation network", Seismological Research Letters, 83, No. 1, pp. 59-66.

[9]. Lermo, J. \& F.J. Chavez Garcia (1994), "Are microtremors useful in site response evaluation ?", Bulletin of the Seismological Society of America 84(5), pp. 1350-1364

[10]. Mittal, H.; Kamal; Kumar, A. and Singh, S.K. (2013), "Estimation of site effects in Delhi using standard spectral ratio", Soil Dynamics and Earthquake Engineering, Vol. 50, pp. 53-61

[11]. Mittal, H.; Kumar, A.; Ramhmachuani, R. (2012), "Indian National Strong Motion Instrumentation Network and Site Characterization of Its Stations", International Journal of Geosciences, 2012, 3, pp. 1151-1167.

[12]. Parolai, S. (2012), "Investigation of site response in Urban area using earthquake data and seismic noise", DOI: $\quad$ 10.2312/GFZ.NMSOP-2_ch14, www.gfzpublic.gfz-potsdam.de.

[13]. PESMOS, Program for Excellence in Strong Motion Studies, www.pesmos.in

[14]. Pitilakis, K (2004), "Site Effects", Recent advances in earthquake geotechcnial engineering and microzonation, Springer, Neatherlands, pp. 139-197.

[15]. Raptakis, D., Theodulidis, N. \& Pitilakis, K. (1998a), "Data Analysis of the Euroseistest Strong Motion Array in Volvi (Greece): Standard and Horizontal to Vertical Ratio Techniques", Earthquake Spectra, (14)1, pp. 203-224.

[16]. Riepl, J., Bard, P.-Y., Hatzfeld, D., Papaioannou, C. \& Nechstein, N. (1998), "Detailed Evaluation of SiteResponse Estimation Methods across and along the Sedimentary Valley of Volvi (Euroseistest)", Bulletin of the Seismological Society of America, (88)2, pp. 488-502.

\section{BIOGRAPHIES}

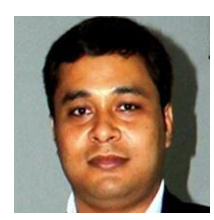

Sasanka Borah, Research Scholar, Department of Civil Engineering, Assam Engineering College, Interests: Earthquake Engineering / Geotechnical Earthquake Engineering

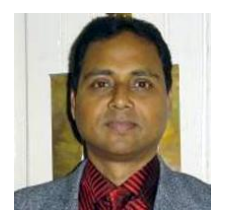

Dr. Diganta Goswami, Associate Professor, Department of Civil Engineering, Assam Engineering College, Specialization: Geotech

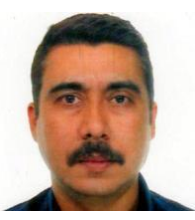

Dr. Jayanta Pathak, Professor, Department of Civil Engineering, Assam Engineering College, Specialization: Structures 